\title{
GENÉTICA DE COFFEA. XXVI. HEREDITARIEDADE DO PORTE REDUZIDO DO CULTIVAR CATURRA ${ }^{(1)}$
}

ALCIDES CARVALHO. HERCULANO PENNA MEDINA FILHO (2), LUIZ CARLOS FAZLOLI (2) e WALDIR MARQUES DA COSTA (2), Seçāo de Genética, Instituto Agronômico.

\begin{abstract}
RESUMO
A mutação de Coffea arabica, conhecida sob a denomınação de Caturra, caracteriza-se pela redução do comprimento médio dos internódios dos ramos ortotrópicos e plagiotrópicos, o que diminui a altura das plantas, conferindo-lhes um aspecto compacto. Surgiu provavelmente no Bourbon Vermelho, e sua produção se assemelha à deste cultivar. Devido a suas caracteristicas, a densidade de plantio poderá ser aumentada, refletindo favoravelmente na produçãc por área, e facilitando tanto a colheita como os tratos culturais e fitossanitários. A análise genética, realizada a partir dos tipos paternais Caturra e Normal, que abrangeu a classificação de plantas $\mathbf{S}_{1}, \mathbf{S}_{9}, \mathbf{S}_{3}, \mathbf{S}_{1}$ e $\mathbf{S}_{5}, \mathbf{F}_{1}, \mathbf{F}_{2}$ e $\mathrm{BC}$ e cruzamentos-testes $\mathrm{e}$ seus descendentes, num total de 55.516 plantas, indicou que o porte reduzido do Caturra é controlado por um fator genético simples, ao qual foi proposto o simbolo Ct. A dominância é completa, sendo indistinguiveis os cafeeiros de genótipos CtCt e Ctct. Dado o interesse que apresentam as plantas de porte reduzido, o fator Caturra vem sendo transferido a outros cultivares de C. arabica de maior interesse econômico.
\end{abstract}

\section{INTRODUC̣ÃO}

Não há informações completas sobre a origem do cafeeiro Caturra (Coffea arabica cv. Caturra Vermelho e cv. Caturra Amarelo). Infor-

(1) Trabalho apresentado na $35^{\ddagger}$ Reunião Anual da Sociedade Brasileira para o Progresso da Ciência, Belém (PA), 1983, e parcialmente executado com auxílio do Instituto Brasileiro do Café. Recebido para publicação a 28 de março de 1983.

(2) Com bolsa de pesquisa do Conselho Nacional de Desenvolvimento Científico e Tecnológico $(\mathrm{CNPq})$. 
mações obtidas no município de Siqueira Campos (ES), onde existiam, em 1937, várias plantaçōes desse café, indicaram que as sementes originais haviam provindo do povoado de Lessa, município de Manhumirim (MG), não sendo conhecido se aí surgiu como mutação ou se algum lavrador o trouxe de outra localidade. MENDES et alii (14), ao visitarem propriedades agrícolas em Siqueira Campos, notaram a existência de plantas com frutos vermelhos (Caturra Vermelho) e amarelos (Caturra Amarelo). Também não há informações se esse Caturra de frutos amarelos já existia em Lessa ou se originou por hibridação no Espírito Santo, com cafeeiro de frutos amarelos ou ainda por mutação do alelo Xc para xc, o que é bastante freqüente $(11,12)$.

Duas amostras de sementes foram recebidas em Campinas, em 1937, uma de Caturra Vermelho (C 477), outra de Amarelo (C 476), as quais deram plantas bastante uniformes, todas de porte reduzido. Apresentavam aspecto sadio, folhas pouco mais largas e de coloração verde mais intenso do que as do cultivar Bourbon Vermelho de C. arabica, enquanto as flores, frutos e sementes eram semelhantes aos desse cultivar. $O$ que caracteriza o Caturra é, como o próprio nome indica, a sua menor altura. Isso é devido ao reduzido tamanho de seus internódios, tanto da haste principal como dos ramos laterais, do qual resulta urn aspecto mais compacto da planta. Seu elevado potencial de produção, associado à menor altura, confere-lhe vantagens econômicas.

Vários estudos vêm sendo realizados para aproveitamento comercial das formas com porte reduzido, não apenas entre as espécies anuais (15, 16), como também entre as plantas perenes $(2,8)$. Haja vista o realce que se vem dando aos pessegueiros de porte anão, pela facilidade de colheita e de tratos culturais e possibilidade de adotar maior densidade de plantio (8) e aumentos substanciais de produção por área. Os cultivares de arroz e trigo de menor altura, além de poderem ser plantados a distâncias menores, mostram-se mais resistentes ao acamamento após o emprego de maior quantidade de fertilizantes (16), resultando em produções mais abundantes.

O café Caturra, a exemplo de outros cultivares de porte reduzido de C. arabica, como Pacas, Vila Sarchi, São Bernardo, San Ramón e Vila Lobos, apresenta maior facilidade de colheita, além de permitir um plantio a espaçamentos mais densos, como já vem sendo feito em várias localidades $(6,7,12)$. Daí o interesse que despertou o setudo do Caturra e a caracterização genética do fator responsável pelo tamanho mais reduzido dos internóidios da haste principal e de seus ramos laterais.

As linhagens de Caturra, embora apresentem boa capacidade prodintiva, não deram colheitas continuamente elevadas no Estado de. São Paulo, provavelmente devido à falta de rusticidade (4) \& de adaptação à longa estiagem, que normalmente se verifica neste Estado. No entanto, em regióes com deficiência hídrica menos prolongada, como em Costa Rica e na Colômbia, o Caturra se desenvolve bem e produz abundantes colheitas, o que o torna de bastante interesse econômico $(\mathbf{9}, \mathbf{1 3}, 18)$. 
Em vista de o Caturra ter apresentado pouca adaptação em São Paulo, foi utilizado em numerosas hibridações, principalmente com o cultivar Mundo Novo de C. arabica, tendo em vista a transferência de suas características de porte reduzido para esse cultivar, que, além de produtivo, é bastante rústico. Dessas hibridações, resultaram as atuais linhagens de Catuaí, bem adaptadas a quase todas as regiões cafeeiras onde vêm sendo testadas $(\mathbf{3}, \mathbf{5})$.

Dada a importância do Caturra e seu valor nos trabalhos de melhoramento, julgou-se conveniente a realização de uma análise genética para esclarecer o tipo de herança da sua principal característica, que é o porte reduzido. Embora referências já tenham sido feitas sobre a herança do Caturra, resolveu-se, neste trabalho, apresentar os dados pormenorizados obtidos durante quarenta anos de observaçōes sobre a análise envolvendo esse fator genético.

\section{MATERIAL E MÉTODOS}

Para a análise genética, escolheram-se plantas de Caturra Vermelho (prefixo C 477 da Seção de Genética), Caturra Amarelo (C 476) e outras introduções desse cultivar (C 1036, C 811 a C 818), que se caracterizavam pelo vigor e boa produtividade. Esses cafeeiros foram cruzados principalmente com plantas de cultivares Arábica (C. arabica cv. Arábica) e Bourbon Vermelho (C. arabica cv. Bourbon Vermelho), tomados como padrão na análise genética (1). Todavia, algumas hibridações com outros cultivares de C. arabica de porte normal foram tamóm realizadas, sendo os resultados aproveitados na análise genética. A técnica adotada para as autofecundaçōes das flores e emasculações dos botōes florais para as hibridaçōes foram as tradicionalmente utilizadas pela Seção de Genética (10). Cruzamentos recíprocos foram feitos, sempre que possível, para a confirmação dos resultados.

As mudas, com aproximadamente 12-18 meses de idade, foram classificadas em viveiros nas classes porte reduzido (Caturra) e normal, baseando-se no tamanho dos internódios e no aspecto geral, pois o Caturra, mesmo em viveiro, apresenta folhas maiores, mais largas, e de uma coloração verde mais intensa. Muitos cafeeiros resultantes de autopolinizaçōes artificiais ou hibridações foram plantados no campo, em experimentos específicos, para avaliar a produção e o seu potencial para fins de melhoramento $(3,4)$.

Os dados de segregação obtidos num período de quarenta anos foram agrupados em populaçōes autofecundadas $S_{1}, S_{2}, S_{3}, S_{4}$ e $S_{5}$, populações $\mathrm{F}_{1}, \mathrm{~F}_{2}, \mathrm{BC}$ e cruzamentos-teste. Os valores de $\chi^{2}$ foram calculados de acordo com a segregação esperada para um par de fatores dominantes, utilizando-se o fator de correção de Yates (17).

Devido ao elevado número de plantas examinadas nas várias populações, serão apresentados apenas os dados referentes a algumas populaçōes segregantes e os resultados totais para cada conjunto. 


\section{RESULTADOS DISCUSSão}

Realizaram-se autopolinizações dos cafeeiros Caturra e hibridações com representantes de cultivares de porte normal, obtendo-se os dados que se seguem.

\subsection{Autopolinizações de plantas Caturra}

Um total de 62 plantas derivadas das introduções C. 476, C 477, C 1036 e C 811 a C 814 foram autopolinizadas, obtendo-se 6.174 plantas, todas do tipo Caturra, indicando serem homozigotas para essa caracteristica (Quadro 1).

QUADRO 1. Progênies obtidas de flores autopolinizadas de cafeeiros Caturra

\begin{tabular}{|c|c|c|c|c|c|c|}
\hline Cafeeiros & $\begin{array}{l}\text { Plantas } \\
\text { Caturra } \\
\text { obtidas }\end{array}$ & Cafeeiros & $\begin{array}{l}\text { Plantas } \\
\text { Caturra } \\
\text { obtidas }\end{array}$ & Cafeeiros & & $\begin{array}{l}\text { Plantis } \\
\text { Caturra } \\
\text { obtidas }\end{array}$ \\
\hline & $\mathrm{n}^{\circ}$ & & $\mathrm{n}^{0}$ & & & $\mathrm{n}^{\circ}$ \\
\hline $476-2$ & 126 & $477-1$ & 81 & 811 & & 82 \\
\hline $476-3$ & 238 & $477-2$ & 40 & 812 & & 85 \\
\hline $476-3-6$ & 204 & $477-4$ & 26 & 813 & & 140 \\
\hline $476-3-10$ & 148 & $477-5$ & 27 & 814 & & 115 \\
\hline $476-3-12$ & 171 & $477-7$ & 3 & 815 & & 53 \\
\hline $476-8$ & 45 & $477-8$ & 30 & 816 & & 54 \\
\hline $476-11$ & 198 & $477-9$ & 333 & 817 & & 86 \\
\hline $476-13$ & 43 & $477-10$ & 10 & 818 & & 465 \\
\hline $476-13-21$ & 89 & $477-11$ & 14 & $1036-8$ & & 44 \\
\hline $476-14$ & 135 & $477-12$ & 101 & $1036-18$ & & 111 \\
\hline $476-15$ & 39 & $477-12-17$ & 78 & 1036-33 & & 30 \\
\hline $476-15-1$ & 84 & $477-12-13$ & 140 & $1036-34$ & & 60 \\
\hline $476-15-10$ & 84 & $477-13$ & 6 & $1036-36$ & & 145 \\
\hline $476-15-11$ & 65 & $477-14$ & 58 & $1036-37$ & & 138 \\
\hline $476-15-21$ & 4 & $477-14-19$ & 72 & $1036-58$ & & 29 \\
\hline $476-15-24$ & 36 & $477-17$ & 23 & $1036-44$ & & 38 \\
\hline $476-15-10-1$ & 9 & $477-20$ & 22 & $1036-59$ & & 68 \\
\hline $476-15-23$ & 100 & $477-20-3$ & 128 & $1036-43$ & & 100 \\
\hline $476-17$ & 57 & $477-21$ & 431 & & & - \\
\hline $476-21$ & 52 & $477-21-21-7$ & 25 & & & \\
\hline \multirow{3}{*}{$476-21-13$} & 77 & LC 477 & 150 & & & \\
\hline & & LC $477-2$ & 303 & & & \\
\hline & & LC $477-5$ & 226 & & Total & 6.174 \\
\hline
\end{tabular}

\subsection{Hibridações entre plantas Caturra e Normal}

Foram realizados ao todo 120 cruzamentos entre plantas Caturra com cafeeiros de porte normal (populações $F_{1}$ ), pertencentes principalmente aos cultivares Arábica e Bourbon de C. arabica. Obtiveram-se 3.868 cafeeiros, todos do tipo Caturra, indicando a dominâricia da característica Caturra (Quadro 2). 


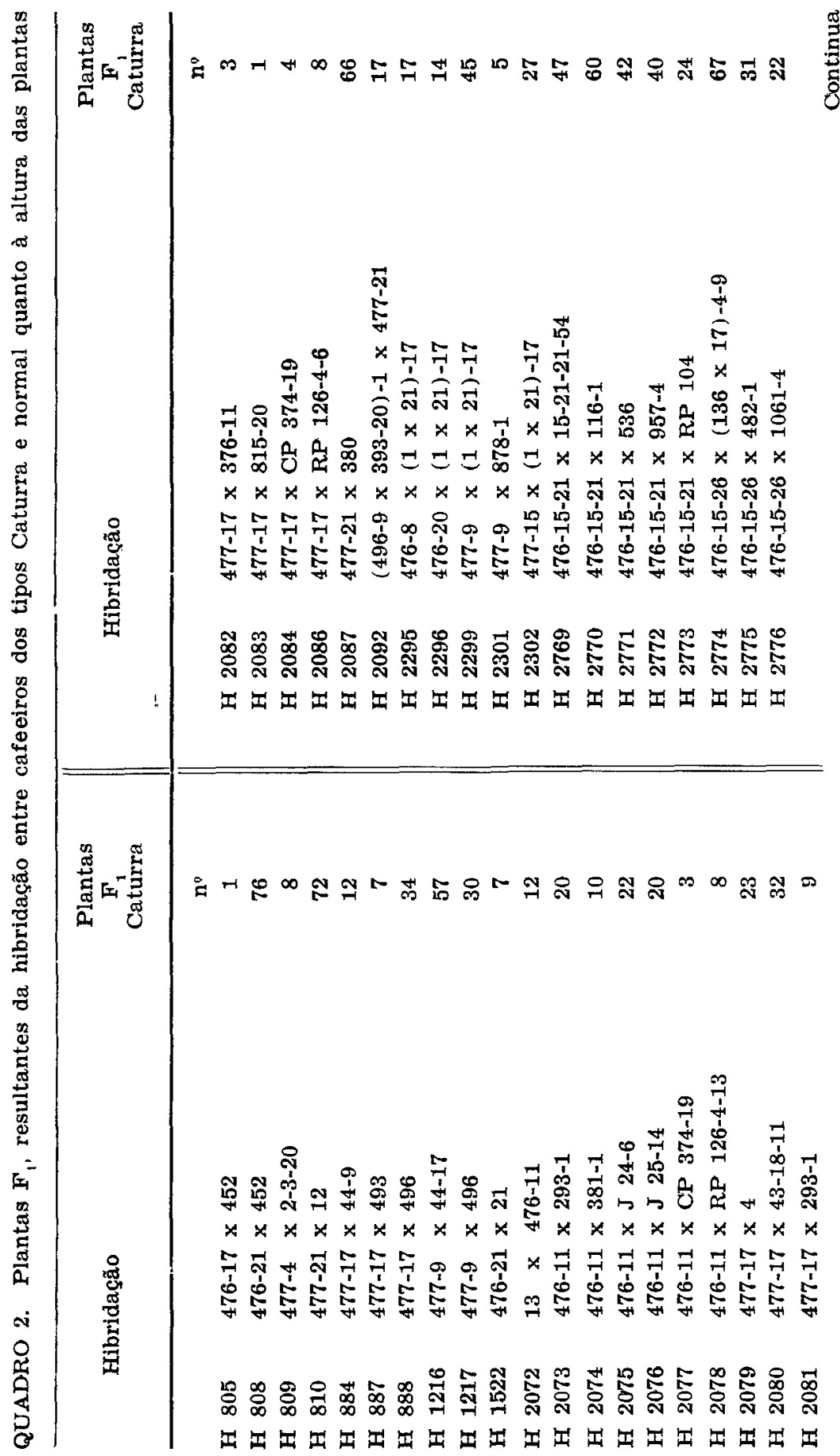




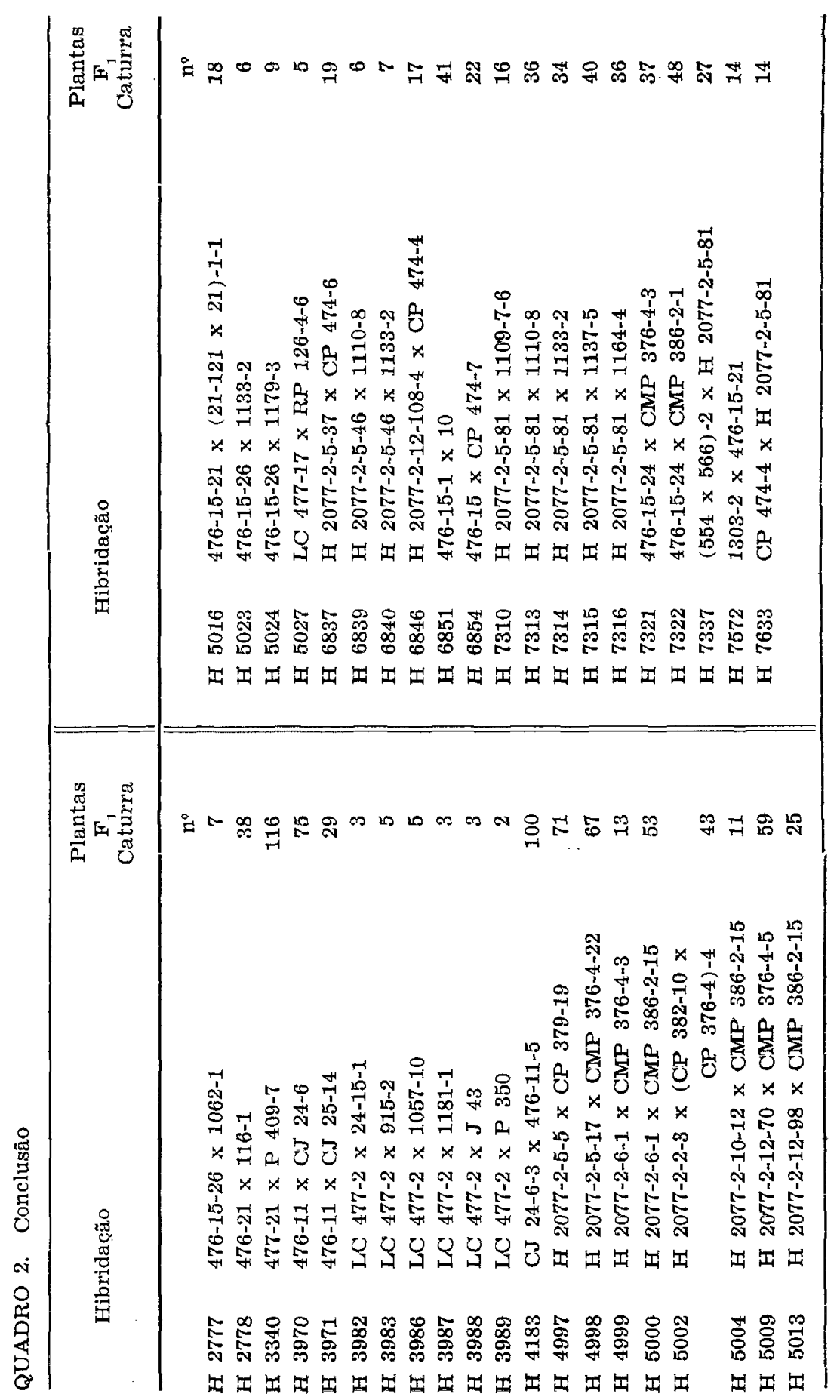




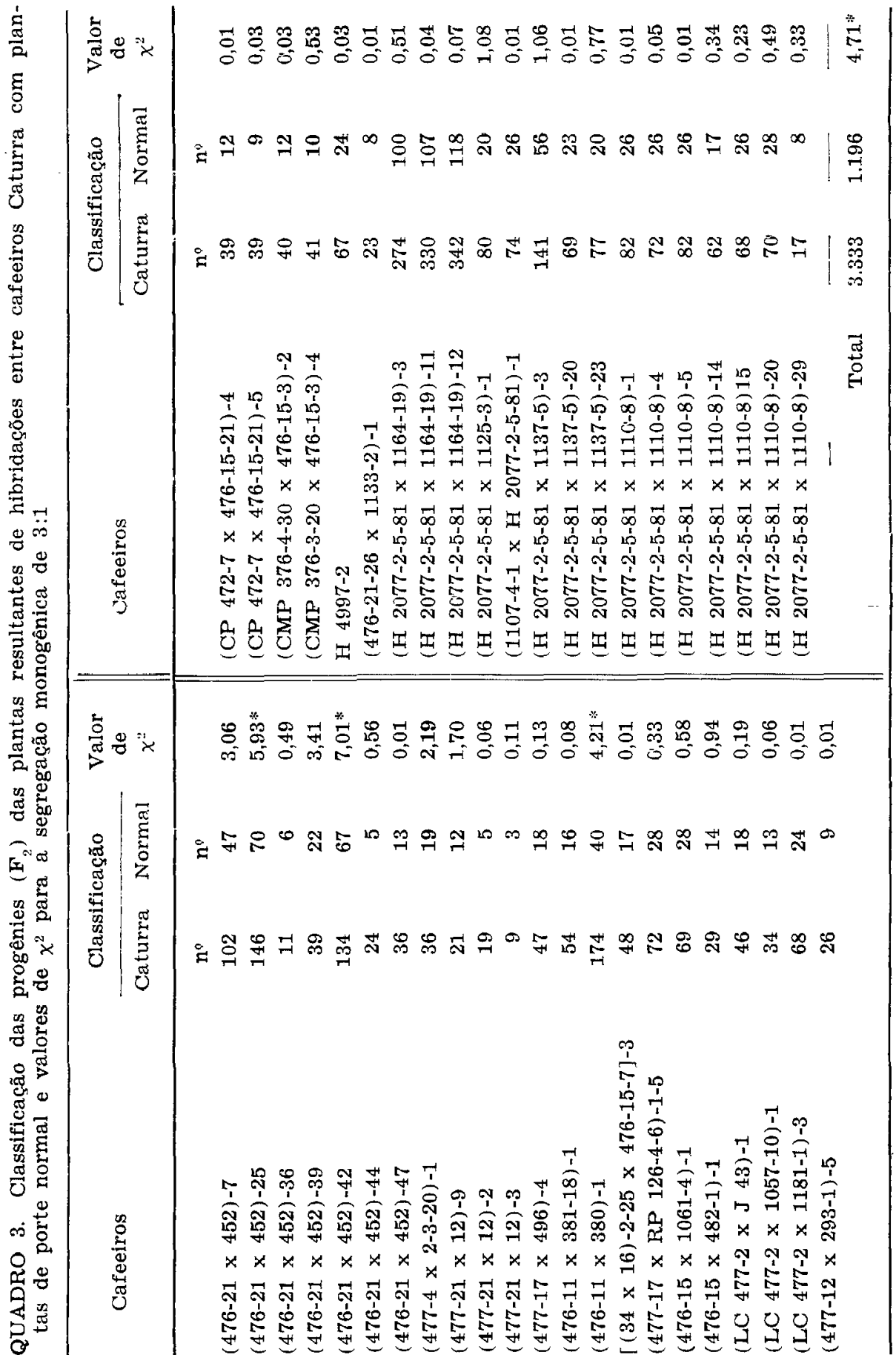




\section{3 $\quad F_{2}$ : Normal $x$ Caturra}

Autofecundaram-se flores de 43 cafeeiros $F_{1}$, resultantes da hibridação entre plantas Caturra e normais, obtendo-se um total de 3.333 plantas Caturra e 1.196 normais $\left(x^{2}=4,71\right)$, relação significativa $(5 \%)$ para a segregação monogênica de 3:1 (valor tabular de $\chi^{2}$ de 3,84) (Quadro $3)$. Os cálculos de $\chi^{2}$ ajustados para cada um dos $43 F_{2}$ revelaram-se, no entanto, não significativos, com exceção de três populações.

\subsection{Retrocruzamentos (Normal x Caturra) $\times$ Caturra}

Realizaram-se onze retrocruzamentos entre plantas $F_{1}$ (Normal $x$ Caturra) e plantas homozigotas Caturra, resultando em 314 cafeeiros, todos do tipo Caturra (Quadro 4).

QUADRO 4. Plantas resultantes de retrocruzamentos de híbridos $F_{1}$ (Normal versus Caturra) com cafeeiros Caturra

\begin{tabular}{|c|c|c|}
\hline & Retrocruzamentos & $\begin{array}{l}\text { Plantas } \\
\text { Caturra }\end{array}$ \\
\hline & & $n^{\circ}$ \\
\hline H 1208 & $(476-21 \times 452)-36 \times 476-831$ & 38 \\
\hline H 1210 & $(476-21 \times 452)-39 \times 476-8 \ldots$ & 60 \\
\hline H 1212 & $(477-4 \times 2-3-20)-1 \times 477-4 \ldots$ & 2 \\
\hline H 1214 & $(477-4 \times 2-3-20)-3 \times 477-4 \ldots$ & 10 \\
\hline H 1215 & $(477-4 \times 2-3-20)-3 \times 477-21$ & $\mathbf{5}$ \\
\hline H 1351 & $(477-4 \times 2-3-20)-1 \times 477-4 \ldots \ldots \ldots$ & 25 \\
\hline H 1353 & $(477-4 \times 2-3-20)-5 \times 477-4 \ldots \ldots$ & 23 \\
\hline H 1354 & $(477-17 \times 496)-4 \times 477-47 \ldots$ & 91 \\
\hline H 1357 & $(477-21 \times 12)-2 \times 477-21$ & 16 \\
\hline H 1358 & $(477-21 \times 12)-4 \times 477-2 \ldots \ldots \ldots \ldots$ & 15 \\
\hline H 7347 & $(837 \times 1036-37)-2-1-2 \times$ H $2077-2-5-81$ & 29 \\
\hline & $\operatorname{Total} \ldots \ldots \ldots \ldots$ & 314 \\
\hline
\end{tabular}

\subsection{Retrocruzamentos (Normal x Caturra) x Normal}

Foram feitos 59 retrocruzamentos entre híbridos $F_{1}$ (Normal $x$ Caturra) com cafeeiros de porte normal (cruzamentos-teste). Verificou-se segregação de 1.523 Caturra e 1.454 normais, cujo valor de $x^{2}=1,55$ não é significativo a $5 \%$ (Quadro 5). Os valores ajustados de $\chi^{2}$ para cada cruzamento-teste não foram significativos para a relàção de 1:1, com exceção de um único caso, cujo valor de $\chi^{2}$ foi 4,56 . 
QUADRO 5. Classificação das plantas resultantes de retrocruzamentos de híbridos F. (Caturra $x$ Normal) com cafeeiros de porte normal (cruzamento-teste)

\begin{tabular}{|c|c|c|c|}
\hline \multirow{2}{*}{ Retrocruzamento } & \multicolumn{2}{|c|}{ Plantas } & \multirow{2}{*}{$\begin{array}{c}\text { Valor } \\
\text { de } \\
\chi^{2}\end{array}$} \\
\hline & Caturra & Normal & \\
\hline & $\mathbf{n}^{0}$ & $\mathrm{n}^{\mathbf{0}}$ & \\
\hline H $1207(476-21 \times 452)-36 \times 452$ & 15 & 23 & 1,24 \\
\hline Н $1209(476-21 \times 452)-39 \times 452$ & 29 & 22 & 0,71 \\
\hline H $1211(477-4 \times 2-3-20)-1 \times 2-3-20$ & 1 & $\mathbf{5}$ & 1,50 \\
\hline H $1213(477-4 \times 2-3-20)-3 \times 2-3-20$ & 20 & 20 & 0,02 \\
\hline H $1226(477-21 \times 12)-9 \times 12-13$ & 3 & 4 & 0,00 \\
\hline H $1355(477-17 \times 496)-4 \times 496$ & 60 & 63 & 0,03 \\
\hline H $3341(477-21 \times 380)-1 \times 380$ & 53 & 50 & 0,04 \\
\hline H $3716(476-15-21 \times 15-21-21-54)-1 \times 12$ & 12 & 14 & 0,09 \\
\hline H $3717(476-15 \times 954-7)-2 \times 12$ & 54 & 54 & 0,01 \\
\hline Н $3718[476-15-26 \times(136 \times 17)-4] 4 \times 12$ & 6 & 8 & 0,07 \\
\hline H $37941184 \times(476-15 \times 15-21-21-54)-1$ & 24 & 18 & 0,59 \\
\hline Н $37951184 \times(476-15-21 \times 954-7)-2$ & 21 & 10 & 3,23 \\
\hline Н $37961184 \times[476-15-26 \times(136 \times 17)-4-9]-2$ & 26 & 33 & 0,61 \\
\hline Н $37971184 \times[476-20 \times(1 \times 21)-1-17]-5$ & 0 & 4 & 2,25 \\
\hline H $3978(476-15-21 \times 116-1)-2 \times 10$ & 1 & 1 & 0,50 \\
\hline Н $3979[476-15-26 \times(136 \times 17)-4-7]-2 \times 10$ & 15 & 25 & 2,02 \\
\hline H $3980(476-15-26 \times 1062-4)-2 \times 10$ & 50 & 40 & 0,90 \\
\hline H $4005[(500 \times 566)-5-4 \times 476-15-7]-1 \times 10$ & 80 & 87 & 0,22 \\
\hline H $425510 \times(476-1-26 \times 1062-1)-2$ & 103 & 81 & 2,40 \\
\hline Н 4346 (476-11 x 381-18)-1-1 x 1058-6 & 7 & 7 & 0,07 \\
\hline H $4348(476-15-21 \times 15-21-21-54)-2 \times 10$ & 81 & 77 & 0,06 \\
\hline H $4349(476-15-21 \times 116-1)-1 \times 10$ & 3 & 3 & 0,17 \\
\hline H $4350[476-15-26 \times(136 \times 17)-4-9]-2 \times 10$ & 34 & 36 & 0,01 \\
\hline H $4351[476-15-26 \times(136 \times 17)-4-4]-2 \times 1058-1$ & 9 & 8 & 0,00 \\
\hline H $4352(476-15-26 \times 1061-4)-1 \times 1061-4$ & 13 & 11 & 0,04 \\
\hline H $4353(476-5-26 \times 1062-1)-2 \times 10$ & 22 & 19 & 0,10 \\
\hline H $4354(476-5-26 \times 1062-1)-2 \times 1058-1$ & 6 & 4 & 0,10 \\
\hline H $44921225 \times(476-15-21 \times 536)-1$ & 2 & 3 & 0,00 \\
\hline H $460810 \times(476-15 \times 536)-1$ & 20 & 13 & 1,09 \\
\hline H $4660(476-15-21 \times 15-21-21-54)-2 \times 12$ & 12 & 11 & 0,00 \\
\hline H $4661(476-15-21 \times 15-21-21-54)-2 \times 12-13$ & 43 & 39 & 0,11 \\
\hline H $4662(476-15-21 \times 954-7)-2 \times 1058-1$ & 38 & 28 & 1,23 \\
\hline H $4663(476-15-26 \times 1062-1)-2 \times 1058-6$ & 8 & 13 & 0,76 \\
\hline H $4664(476-15-26 \times 1062-1)-2 \times 1058-1$ & 24 & 14 & 2,13 \\
\hline H $46951058-5 \times(476-15-21 \times 536-1)-1$ & 16 & 13 & 0,14 \\
\hline H $46961058-5 \times[476-15-26 \times(136 \times 17)-4-9]-2$ & 26 & 45 & $4,56^{*}$ \\
\hline H $47601225 \times(476-15 \times 536)-1$ & 14 & 14 & 0,04 \\
\hline H $47611225 \times(476-15 \times 536)-2$ & 28 & 22 & 0,50 \\
\hline H 4988 (476-11 x 293-1)-2-4 $\times($ CP $379-19 \times$ CP 374-19-7)-10 & 4 & 4 & 0,12 \\
\hline H $4992(476-11 \times 293-1)-2-11 \times($ CP $379-19 \times$ CP $374-19-7)-10$ & 4 & 2 & 0,17 \\
\hline H $55011216 \times(476-21 \times 116)-1$ & 25 & 23 & 0,02 \\
\hline H $571910 \times[$ LC $477-2 \times(12 \times 240-22)-1]-1$ & 104 & 124 & 1,58 \\
\hline H 6130 (LC $477-2 \times 24-15-1$ ) -1 × 24-2-1 & 85 & 66 & 2,15 \\
\hline H 6131 (LC $477-2 \times 915-2)-1 \times 446-21$ & 71 & 63 & 0,37 \\
\hline H 6132 (LC $477-2 \times 1057-10$ ) -1 x 1057-10-1 & 18 & 18 & 0,03 \\
\hline H 6133 (LC $477-2 \times 1181-1$ ) -3 x 1181-1-1 & 14 & 11 & 0,16 \\
\hline H 6135 (LC 477-2 x J 43)-1 × J 43-8 & 36 & 25 & 1,64 \\
\hline H $6582(1179-2 \times 476-15-21)-2 \times 1179-2$ & 44 & 36 & 0,61 \\
\hline
\end{tabular}


QUADRO 5, Conclusão

\begin{tabular}{|c|c|c|c|}
\hline \multirow{2}{*}{ Retrocruzamento } & \multicolumn{2}{|c|}{ Plantas } & \multirow{2}{*}{$\begin{array}{c}\text { Valor } \\
\text { de } \\
\chi^{2}\end{array}$} \\
\hline & Caturra & Normal & \\
\hline & $\mathbf{n}^{\circ}$ & $\mathbf{n}^{\circ}$ & \\
\hline H $6857(476-15-21 \times 1133-2)-1 \times 1133-2$ & 23 & 27 & 0,18 \\
\hline H 7221 (CMP $376-4-30 \times 476-15-31$ ) $-4 \times$ CP $379-19-4$ & 20 & 25 & 0,35 \\
\hline H 7223 (LC $477-2 \times 915-2$ ) -2 × 915-2 & 16 & 9 & 1,44 \\
\hline H 7218 (MP $376-4-22 \times 476-15-31$ ) -2 2 CP $474-7$ & 3 & 2 & 0,00 \\
\hline H 7219 (MP $376-4-22 \times 47615-31$ ) $-19 \times$ CP $474-7$ & 16 & 20 & 0,25 \\
\hline H 7220 (MP $376-4-22 \times 476-15-31$ ) $-2 \times$ MP $386-2-4$ & 3 & 1 & 0,25 \\
\hline H $7326[476-15-21 \times(21-121-1 \times 21)-1]-1 \times(21-121-1 \times 21)-1-1$ & 7 & $\mathbf{5}$ & 0,08 \\
\hline H $73981061-1 \times(476-15-26 \times 1061-4)-1$ & 6 & 4 & 0,10 \\
\hline H $7504 \quad 1181-1-5 \times[L C 477-2 \times(12 \times 240-22)-1]-1$ & 11 & 9 & 0,05 \\
\hline H 7631 (CP $172-7 \times 476-15-21)-1 \times($ CP $400-16 \times$ CMP $376-4)-3$ & 28 & 22 & 0,50 \\
\hline H 7707 (LC $477-2 \times 24-15-1$ ) -1 x 916-1 & 25 & 16 & 1,56 \\
\hline Total & 1.523 & 1.454 & 1,55 \\
\hline
\end{tabular}

\section{6 $F_{1}$ : Caturra $x$ Caturra (hibridações entre plantas Caturra homozi- gotas)}

Estudaram-se 27 populações (1.009 plantas) resultantes de hibridaçōes entre plantas homozigotas Caturra, obtendo-se apenas plantas de fenótipo Caturra, confirmando-se as informações obtidas pelas autofecundações das introduçōes originais.

\section{7 $\quad F_{2}$ : Caturra $x$ Caturra}

Classificaram-se quatro progênies derivadas por autofecundação de plantas resultantes da hibridação entre plantas Caturra, obtendo-se 487 plantas, todas do tipo Caturra, corroborando novamente as conclusões obtidas da análise do $F_{1}$ acima e das autofecundaçōes de plantas Caturra.

\section{$3.8 F_{1}$ : (Caturra $x$ Caturra) $x$ Normal}

Cruzamentos, em número de 15 , foram realizados entre híbridos de duas plantas Caturra com plantas normais, resultando em 775 cafeeiros do tipo Caturra.

\section{$3.9 \quad F_{3}$ : Caturra $x$ Normal}

Algumas plantas normais e Caturra das populaçōes $F_{2}$ foram autofecundadas, a fim de estudar suas progênies $F_{3^{*}}$. Observaram-se nas descendências dos cafeeiros normais, em número de 14, ¿penas plantas normais, num total de 1.886 plantas. Nas progênies $F_{3}$ de plantas $F_{2}$ do tipo Caturra, 16 eram constituídas apenas de plantas Caturra (1.495 plantas), enquanto 18 se mostraram heterozigotas, segregando, em suas progênies, plantas Caturra e normais, na proporção de 3:1 (1.598 Caturra para 497 normais; $x^{2}=1,75$ ). Os valores individuais de $x^{2}$ ajustados não são significativos, exceção feita a três progênies cujos valores, 3,85, 5,07 e 7,10, se revelaram significativos (Quadro 6). 
QUADRO 6. Classificação das plantas em Caturra e Normal das progênies $F_{3}$ de cafeeiros Caturra heterozigotos

\begin{tabular}{|c|c|c|c|}
\hline \multirow{2}{*}{ Cafeeiros } & \multicolumn{2}{|c|}{ Plantas } & \multirow{2}{*}{$\begin{array}{c}\text { Valor } \\
\text { de } \\
x^{2}\end{array}$} \\
\hline & Caturra & Normal & \\
\hline & $\mathrm{n}^{\circ}$ & $\mathrm{n}^{\circ}$ & \\
\hline$(477-17 \times 496)-4-2$ & 106 & 25 & 2,14 \\
\hline$(477-21 \times 12)-2-4$ & 189 & 45 & $3,85 *$ \\
\hline$(477-11 \times 381-18)-1-3$ & 3 & 2 & 0,07 \\
\hline$(476-11 \times$ CP $374-19)-2-1$ & 76 & 29 & 0,26 \\
\hline$(476-11 \times R P 126-4-6)-1-5$ & 76 & 29 & 0,26 \\
\hline$(476-11 \times C P 374-19)-2-6$ & 57 & 15 & 0,46 \\
\hline$(476-11 \times$ CP $374-19)-2-7$ & 72 & 28 & 0,33 \\
\hline$(476-11 \times$ CP $374-19)-2-8$ & 77 & 23 & 0,12 \\
\hline$(476-11 \times$ CP $374-19)-2-10$ & 29 & 10 & 0,20 \\
\hline$(476-11 \times C P 374-19)-2-12$ & 30 & 10 & 0,08 \\
\hline$(476-11 \times 381-18)-1-2$ & 38 & 15 & 0,16 \\
\hline$(476-11 \times C P 374-19)-12-359$ & 78 & 22 & 0,33 \\
\hline$(476-11 \times C P 374-19)-12-241$ & 171 & 47 & 1,20 \\
\hline$(476-11 \times C P \quad 374-19)-12-319$ & 88 & 45 & $5,07 *$ \\
\hline$(476-11 \times$ CP $374-19)-12-312$ & 276 & 63 & $7,10 *$ \\
\hline$(476-11 \times C P 374-19)-12-328$ & 125 & 54 & 2,28 \\
\hline$(476-11 \times C P \quad 374-19)-2-10$ & 27 & 15 & 2,03 \\
\hline$(476-11 \times C P 374-19)-2-12$ & 80 & 20 & 1,08 \\
\hline Total $\ldots \ldots \ldots \ldots \ldots$ & 1.598 & 497 & 1,75 \\
\hline
\end{tabular}

\section{$3.10 \quad F_{\ddagger}$ e $F_{5}$ : Caturra $x$ Normal}

Examinando-se 399 cafeeiros dessas populações, verificou-se que 312 Caturra eram homozigotos, pois 21.100 plantas da descendencia tinham o fenótipo Caturra. Onze progênies derivadas de plantas normais deram, em sua descendência, apenas plantas normais, num total cie 706 cafeeircs. Verificou-se ainda que 76 cafeeiros Caturra eram heterozigotos, segreganđo na proporção de $3: 1$, isto é, 3.401 plantas Cazurra para 1.106 normais (valor de $x^{2}=0,48$ ) ; com exceção de duas progênies, nas quais os valores de $\chi^{2}$ ajustados foram significativos $(4,38$ e 4,48$)$, todos os demais foram não-significativos (Quadro 7).

\section{$3.11 F_{2}$ : (Caturra $x$ Normal) $x$ Normal}

Examinaram-se onze progênies, sendo seis de plantas normais e cinco de plantas Caturra. As seis progênies de cafeeiros normais deram um total de 1.409 plantas normais. Os cafeeiros Caturra revelaram-se heterozigotos, segregando na proporção de $3: 1 \quad\left(562: 162 ; \chi^{2}=2,52\right)$. Os valores de $\chi^{2}$ ajustados revelaram-se significativos para duas progênies, com excesso de plantas Caturra (Quadro 8). 


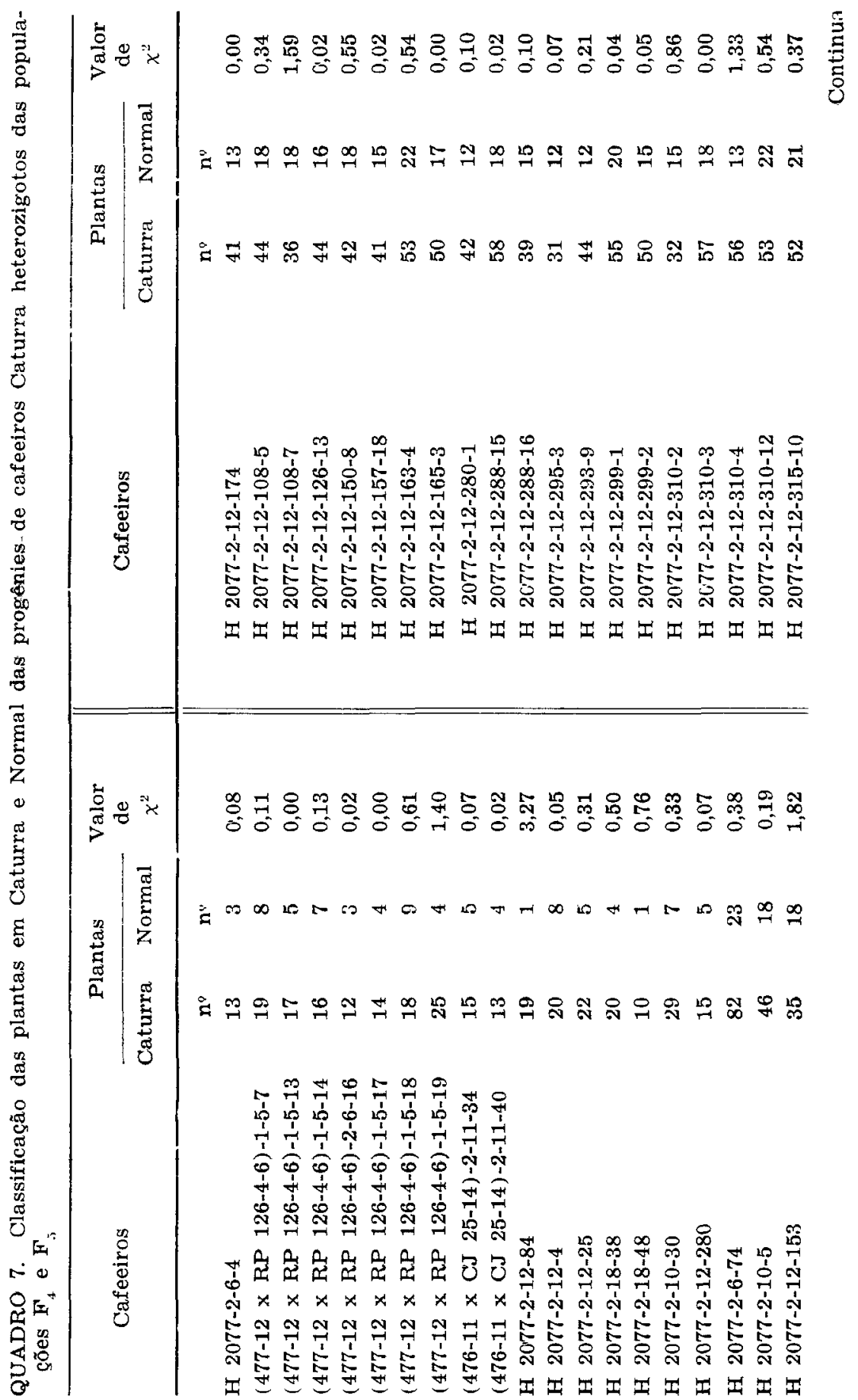




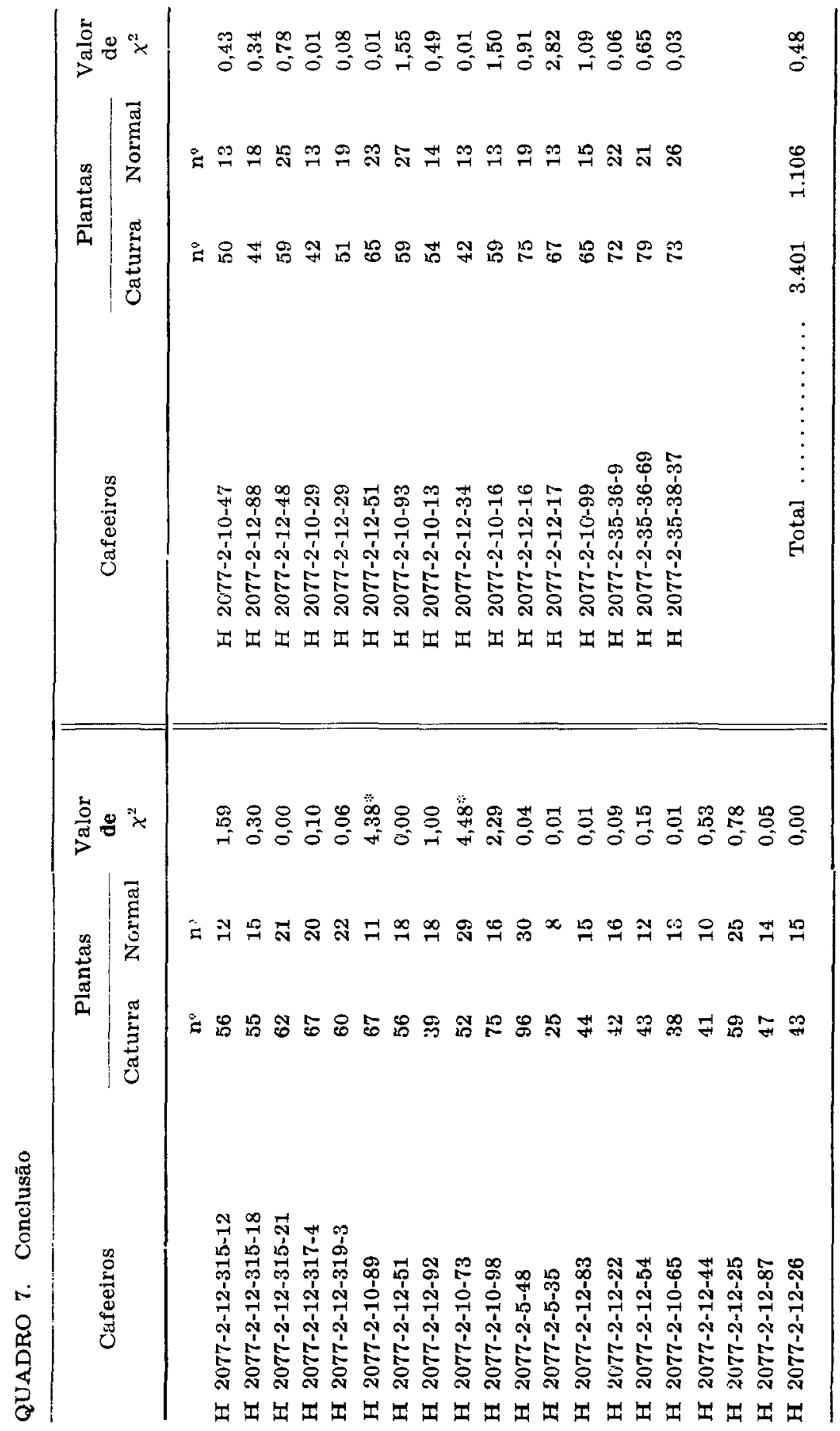


QUADRO 8. Classificação das plantas em Caturra e Normal, provenientes de cafeeiros Caturra das populaçōes $F_{2}$ (Caturra $\mathrm{x}$ Normal)

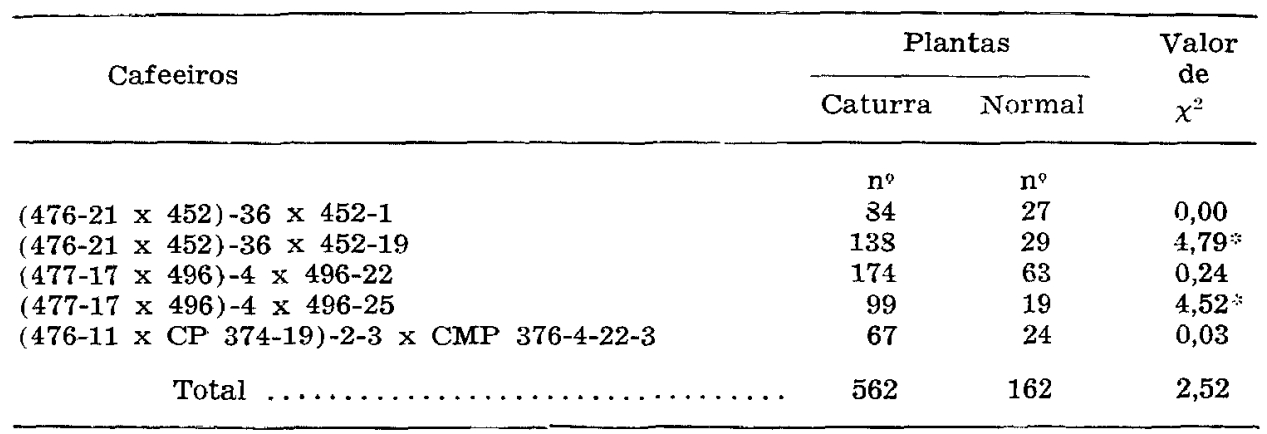

\section{$3.12 F_{2}$ : (Caturra $x$ Normal) $x$ Caturra}

Dos cinco cafeeiros Caturra examinados dessas populações, dois revelaram-se homozigotos, dando um total de 786 plantas Caturra, enquanto três se mostraram heterozigotos, dando 534 plantas Caturra e 141 normais, com valor de $\chi^{2}$ ajustado de 5,87 significativo, tal como ocorreu com uma das progênies examinadas.

\section{DISCUSSÃO E CONCLUSõeS}

A análise genética realizada abrangeu a classificação de um grande número de mudas de 12 a 18 meses em grupos de porte pequeno (Caturra) e porte normal. Realizada em viveiro, essa classificacão se revelou às vezes difícil, em decorrência da variabilidade ambiente que influi sobre o desenvolvimento das mudas, mesmo quando se procura dispensar tratos culturais idênticos. Em plantas adultas, no campoo, essa influência é menor, e as plantas puderam ser classificadas sem dificuldades. Todavia, muitas populações somente foram classificadas em viveiro, pela impossibilidade de transplantação para o campo. Esse fato talvez explique o excesso de plantas em uma das classes em algumas das populaçōes indicadas nos quadros $3,5,6,7$ e 8 , as quais, embora contendo número razoável de indivíduos, deram valores significativos de $\chi^{2}$, enquanto as demais segregaram normalmente, como esperado.

Essa análise genética, que envolveu o estudo de mais de 55.000 plantas num período de quase quarenta anos, revelou-se de particular interesse, em vista do valor econômico do Caturra, que tem porte reduzido aliado a uma boa capacidade produtiva. Os dados apresentados referentes aos cruzamentos-teste, às populações $F_{2}, F_{3}$ e $F_{4}$, indicam segregação para um par de alelos de natureza dominante, identificado pelo simbolo $\mathbf{C t}$, com efeitos sobre a redução do comprimento dos internodios da haste principal e dos ramos plagiotrópicos, dando aspecto compacto às plantas. A dominância é completa, sendo indistinguiveis os cafeeiros de genótipos CtCt e Ctct. 


\section{SUMMARY}

\section{GENETICS OF COFFEA. XXVI. INHERITANCE OF THE SHORT STATURE TRAIT OF 'CATURRA' COFFEE}

Caturra coffee plants (C. arabica) have short stature and compact growth habit due to the reduced internode length of both orthotropic and plagiotropic branches. This mutation - probably originated in the $\mathrm{cV}$ Bourbon Vermelho is agronomically desirable since planting density may be increased, and harvest as well as phytosanitary treatments are facilitated. The inheritance of that trait was investigated by nursey and field scoring of over $\mathbf{5 5 , 0 0 0}$ plants of populations $S_{1}, S_{2}, S_{3}, S_{4}$ and $S_{5}$ of the original accessions and $F_{1}, F_{2}, F_{3}, B C$ and test crosses derived from crosses of Caturra with normal cultivars. It was concluded that the short stature of Caturra is controled by a single dominant factcr to which was assigned the symbol ct. Owing to its economic value, this allele $\mathrm{Ct}$ is being transferred to high yielding cultivars of C. arabica.

\section{REFERENCIAS BDEIOGRAFICAS}

1. ANTUNes FIlHo, H. \& CARVAlHo, A. Genetics of Coffea. XVI. The variety typica as a standard for genetical studies of Coffea arabica. Journal of Heredity, 48:110-117, 1957.

2. Carvalho, A.; MEdina Filho, H. P.; FAzUOl, L. C.; COSTA, W. M. Análise genética de fatores que ređuzem a altura das plantas em Coffea arabica L. In: COLŌQUIO. ASSOCIATION SCIENTIFIQUE INTERNATIONALE DU CAFÉ, Salvador, 1982. p.57-58.

3. —_ MONACO, L. C. Transferência do fator Caturra para o cultivar Mundo Novo de Coffea arabica. Bragantia, Campinas, 31:379-399, 1972.

4. —- ;CARANARI, H. J.; ANTUNES FILHO, H.; MONACO, L. C. Melhoramento do cafeeiro. XXII. Resultados obtidos no Ensaio de Seleções Regionais de Campinas. Bragantia, Campinas, 20:711-740, 1961.

5. EL CATUAI: una experiencia nueva. Noticiero del Café, San José, Costa Rica, 5(178):1-2, 1979.

6. GONZALEZ, J. A. Variedades de café de importancia en El Salvador. In: MANUAL técnico del cultivo del café en El Salvador. Santa Tecla, El Salvador, Instituto Salvadoreño de Investigaciones del Café, 1975. p.19-21.

7. GONZALEZ, J. P. \& CAMPOS, E. C. El café en Costa Rica. Oficina del Café, 1981. 18p. (Informe geral)

8. HANSCHE, P. E.; ClaRoN, O. H.; BENTEL, J.; BERES, W.; DOYLE, J. The commercial potential of dwarf fruit trees. California Agriculture, $33(9): 4-6,1979$.

9. INFORME ANUAL DE LABORES. Programa Cooperativo Oficina del Cafe, 1980. San José, Costa Rica, Ministério de Agricultura y Ganaderia, 1981. p.29-46.

10. KRUG, C. A. Controle de polinização nas flores do cafeeiro. Campinas, Instituto Agronômico, 1937. 12p. (Boletím técnico, 15)

11. — - \& CARVAlho, A. Genética de Coffea. III. Hereditariedade da cor amarela dos frutos. Campinas, Instituto Agronomico, 1940. 16p. (Boletim técnico, 82) 
12. KRUG, C. A.; MENDES, A. J. T.; CARVALHO, A. Taxonomia de Coffea arabica L. II. Coffea arabica L. var. Caturra e sua forma Xanthocarpa. Bragantia, Campinas, 9:157-163, 1949.

13. LITTLE, T. M. \& HILLS, F. J. Agricultural Experimentation. New York, Wiley, 1978. 350p.

14. MENDES, J. E. T.; KRUG, C. A.; BERGAMIN, J. Relatório de uma viagem de estudos sobre a lavoura cafeeira nos Estados do Rio de Janeiro e Espírito Santo. Boletim da Superintendência dos Serviços do Café, São Paulo, 20:1025-1034, 1094-1104, 1150-1156, 1945. 21:11-29, 74-89, 131-146, 1946.

15. PIJUCKNETT, D. L. \& SMITH, N. J. H. Agricultural research and third world food production. Science, 217:215-220, 1982.

16. RUTGER, J. N. \& PETTERSON, M. L. Improved short stature rice. California Agriculture, 30(6):4-6, 1976.

17. STEEL, R. G. D. \& TORRIE, J. H. Principles and procedures of statistics. New York, McGraw-Hill, 1960. 481p.

18. URIBE HENAO, A. \& SALAZAR ARTAS, N. Distancia de siembra y dosis de fertilizante en la producción de café. Cenicafé, Colombia 32(3):88-105, 1981. 